\title{
Calcium as a Limiting Factor in the Distribution of the Amphipod Gammarus pseudolimnaeus
}

John Kinsley Zehmer

College of William \& Mary - Arts \& Sciences

Follow this and additional works at: https://scholarworks.wm.edu/etd

Part of the Fresh Water Studies Commons

\section{Recommended Citation}

Zehmer, John Kinsley, "Calcium as a Limiting Factor in the Distribution of the Amphipod Gammarus pseudolimnaeus" (1998). Dissertations, Theses, and Masters Projects. Paper 1539626165.

https://dx.doi.org/doi:10.21220/s2-bgag-6r86

This Thesis is brought to you for free and open access by the Theses, Dissertations, \& Master Projects at W\&M ScholarWorks. It has been accepted for inclusion in Dissertations, Theses, and Masters Projects by an authorized administrator of W\&M ScholarWorks. For more information, please contact scholarworks@wm.edu. 
CALCIUM AS A LIMITING FACTOR IN THE DISTRIBUTION OF THE AMPHIPOD GAMMARUS PSEUDOLIMNAEUS

\author{
A Thesis \\ Presented to \\ The Faculty of the Department of Biology \\ The College of William and Mary in Virginia \\ In Partial Fulfillment \\ Of the Requirements for the Degree of \\ Master of Arts
}

by

John Kinsley Zehmer

1998 


\section{APPROVAL SHEET}

This thesis is submitted in partial fulfillment of the requirements for the degree of

Master of Arts

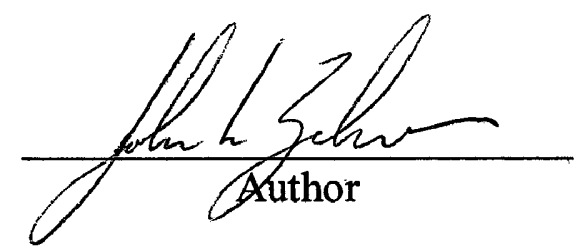

Approved, May 1998
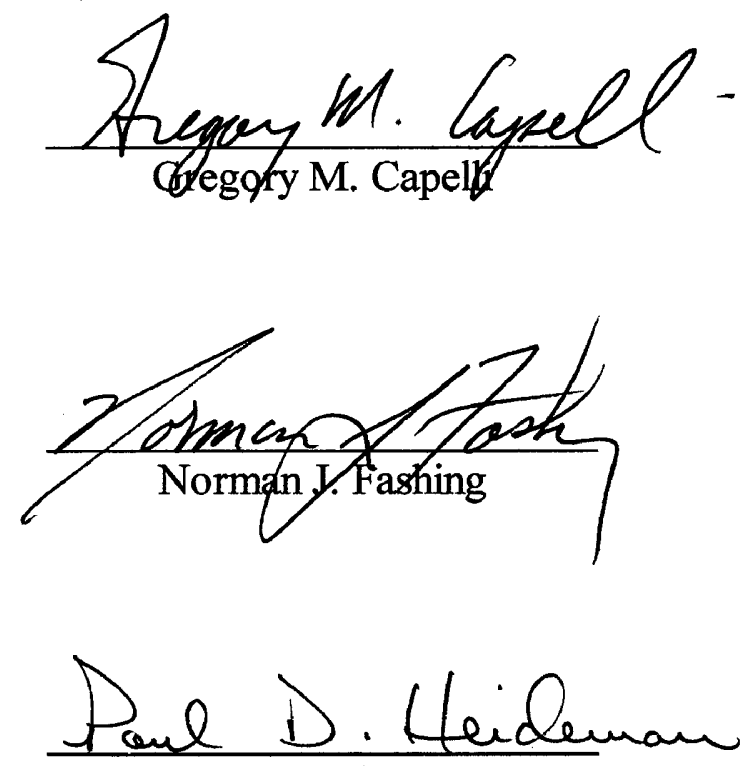

Paul D. Heideman 
for my parents

thank you for your love and support 


\section{TABLE OF CONTENTS}

\section{Page}

ACKNOWLEDGMENTS

$\mathrm{V}$

LIST OF TABLES

vi

LIST OF FIGURES

vii

ABSTRACT

viii

INTRODUCTION

2

ANIMALS AND STUDY AREA

$\begin{array}{ll}\text { MATERIALS AND METHODS } & 7\end{array}$

$\begin{array}{ll}\text { RESULTS } & 11\end{array}$

$\begin{array}{ll}\text { DISCUSSION } & 20\end{array}$

CONCLUSIONS AND FUTURE DIRECTIONS 27

$\begin{array}{ll}\text { REFERENCES } & 29\end{array}$

$\begin{array}{ll}\text { VITA } & 33\end{array}$ 


\section{ACKNOWLEDGMENTS}

The author would like to express his appreciation to the following people:

Dr. Greg Capelli - for his careful consideration of this document. It is better for it.

Dr. Paul Heideman - for his assistance with experimental design and analysis and his valuable advice and support.

Dr. Norman Fashing - for fielding my many questions

Dr. Romuald Lipcius - for his assistance in statistical analysis and his patience with my questions.

Taryn DiFebbo - for her assistance with field work.

Mark Stoetzer - for his assistance with laboratory work. 


\section{LIST OF TABLES}

Table

Page

1. Percent water content of amphipods in the field water balance

12 survey and the field and laboratory water balance experiments 


\section{LIST OF FIGURES}

Figure

Page

1. Schematic of the study sites with chemical data

2. Male and female mortality: results 1

3. Male and female mortality: results 2

4. Berkeley chemical manipulation results

17

5. Pogonia chemical manipulation results

19 


\begin{abstract}
The amphipod Gammarus pseudolimnaeus is abundant throughout the majority of the length of two small streams on the coastal plain of Virginia, but is absent from their upper reaches. The streams exhibit a gradient of dissolved materials and $\mathrm{pH}$, with conductivity ranging from 12 to $250 \mu \mathrm{mhos}$, and $\mathrm{pH}$ ranging from under 6 to 7, from source to lake. General osmoregulatory failure during intermolt does not appear to be limiting the distribution of this amphipod; percent body water content, a general gauge of osmotic stress, was not found to be greater in amphipods closer to the distribution limit, nor does it increase in amphipods displaced above the distribution limit. In the laboratory, males and females maintained in water from above the distribution limit experienced greater mortality than those in water from below the distribution limit. Mortality was closely associated with time of molt. Amphipods in water from above the distribution limit generally lived 1-2 days post-molt while those in water from below the distribution limit lived, on average, 8-10 days post-molt. The addition of $\mathrm{Ca}^{2+}$ to water from above the distribution limit increased post-molt survival to levels observed in those maintained in water from below the distribution limit; raising $\mathrm{pH}$ had no effect on post-molt mortality. Insufficient ambient calcium appears to be a limiting factor in the distribution of G. pseudolimnaeus in these two streams.
\end{abstract}


CALCIUM AS A LIMITING FACTOR IN THE DISTRIBUTION OF THE AMPHIPOD GAMMARUS PSEUDOLIMNAEUS 


\section{Introduction}

Freshwater amphipods are widely distributed among diverse habitats. With densities that may exceed $10,000 / \mathrm{m}^{2}$ (Pennak 1978), they often form an important link between primary and secondary production (Hanson and Waters 1974). However, relatively few studies have examined the environmental conditions affecting or limiting their distribution. Most are either purely descriptive of ranges or suggest connections between distribution and chemical factors (e.g. alkalinity,

$\mathrm{pH}, \mathrm{Ca}^{2+}, \mathrm{Mg}^{2+}$, and conductivity) without determining if those factors are actually limiting.

One of the most commonly mentioned factors is calcium. The distribution of at least one species from most orders of freshwater animals has been associated with this ion (Macan 1961). Calcium is important for intracellular processes and, in many aquatic animals, for maintaining an impermeable membrane (Rasmussen and Bjerregaard 1995; McDonald 1983; Macan 1961). In some crustaceans it is also important for haemocyanin oxygen-binding properties (Mangum 1983; Taylor and Spicer 1986) and for hardening the exoskeleton (Stevenson 1985; Hilton et al. 1984). The distributions of the Gammarid amphipods Gammarus minus Say, $G$. fossarum Koch, G. roeseli Gervais, and G. pseudolimnaeus Bousfield have all been correlated with calcium (Glazier and Gooch 1987; Schrimpff and Foeckler 1985; Mahon 1997). However, Sutcliffe and Carrick (1973) suggested that bicarbonate, 
with which calcium is often associated, was more important than calcium to the distribution of G. pulex (L.)

Freshwater invertebrate diversity generally declines with lower $\mathrm{pH}$ (Schell and Kerekes 1989; Okland and Okland 1986); crustaceans appear to be especially acid intolerant (Havas and Hutchinson 1983; Okland and Okland 1986). Among amphipods, the following lower $\mathrm{pH}$ limits have been reported: G. pulex, 5.7 (Otto and Svensson 1983; Sutcliffe and Carrick 1973), though one survey described this species at pH 4.5 (Pinkster 1972); G. lacustris Sars, 6.0 (Okland and Okland 1986); Hyalella azteca Saussure, 5.6 (Grapentine and Rosenberg 1992; Stephenson and Mackie 1986).

Associations between chemical factors and species distribution can be inferred from survey data, but the covariance of many factors and the interaction among factors make interpretation difficult. For example, although $\mathrm{pH}$ is commonly cited as limiting in many organisms, the threshold where deleterious effects manifest in any given species is influenced by the chemical and physical background. For example, increased dissolved humic substances reduced the mortality of G. pulex in acidic water (Hargeby and Petersen 1988; Hargeby 1990). Increased sodium concentration ameliorated the toxic effects of low pH on $G$. fossarum (Meinel et al. 1985), and calcium level may be especially important in relation to $\mathrm{pH}$ in many animals (Okland and Okland 1985). Therefore, manipulative experiments are important for interpretation of survey results. 
The amphipod Gammarus pseudolimnaeus ${ }^{1}$ is found in two small streams, on the coastal plain of Virginia. Both streams exhibit a strong chemical gradient, including calcium and $\mathrm{pH}$, from source to mouth. G. pseudolimnaeus is abundant throughout most of the length of these streams but has a sharp distribution limit in the upper reaches of both. Mahon (1997), using field displacement experiments, found significantly higher mortality rates above the distribution limit compared with those below. Neither predation nor interspecific competition appeared be factors in the mortality. Based on the mortality pattern, Mahon (1997) speculated that death occurred at molt.

The experiments described here address potential factors limiting the distribution of the amphipod G. pseudolimnaeus. I describe field and laboratory experiments to test the hypothesis that general osmoregulatory failure prevents range expansion. In two laboratory experiments I tested for differences in mortality between males and females. Finally, chemical manipulation experiments in the laboratory tested the hypothesis that $\mathrm{Ca}^{2+}$ and/or $\mathrm{pH}$ are limiting factors.

${ }^{1}$ The specimens closely match published descriptions of Gammarus pseudolimnaeus, a species previously known from the Great Lakes and upper Mississippi drainages. This finding has been confirmed by Dr. John Holsinger of Old Dominion University, who suggests using the designation Gammarus (near) pseudolimnaeus. For convenience, however, the organism will hereafter be referred to in this document as simply Gammarus pseudolimnaeus. 


\section{Animals and Study Area}

The two study streams, designated Berkeley and Pogonia (see Mahon 1997), are located on the coastal plain of Virginia on the campus of The College of William and Mary within a forest preserve. Both arise as springs and flow about $900 \mathrm{~m}$ (Berkeley) and 700m (Pogonia) before confluencing with a small lake. The streams have a very low flow over mostly firm, sand substrate, varying throughout from 0.3 to $10 \mathrm{~m}$ in width with depths generally less than $10 \mathrm{~cm}$. Dissolved $\mathrm{O}_{2}$ is near saturation for most of their lengths, but the streams exhibit a strong gradient of dissolved materials, with conductivity ranging from 12 to $250 \mu$ mhos from source to lake.

G. pseudolimnaeus is abundant throughout most of the length of both streams; however, in the upper reaches of both it declines from abundant to absent over a distance of only a few meters. This area in both streams will be referred to as the distribution limit (DL). The DL in both Pogonia and Berkeley is very low in dissolved materials with conductivities of approximately $49 \mu$ mhos and $28 \mu \mathrm{mhos}$, respectively (Figure 1). The exact location of this area and the associated chemical conditions tend to remain constant (Greg Capelli, personal communication). Sites were established $50 \mathrm{~m}$ above and $15 \mathrm{~m}$ below the DL in Berkeley and $25 \mathrm{~m}$ above and $25 \mathrm{~m}$ below the DL in Pogonia for use or reference in the experiments described below. The upper and lower sites will be referred to as ADL (above the DL) and BDL (below the DL), respectively. 

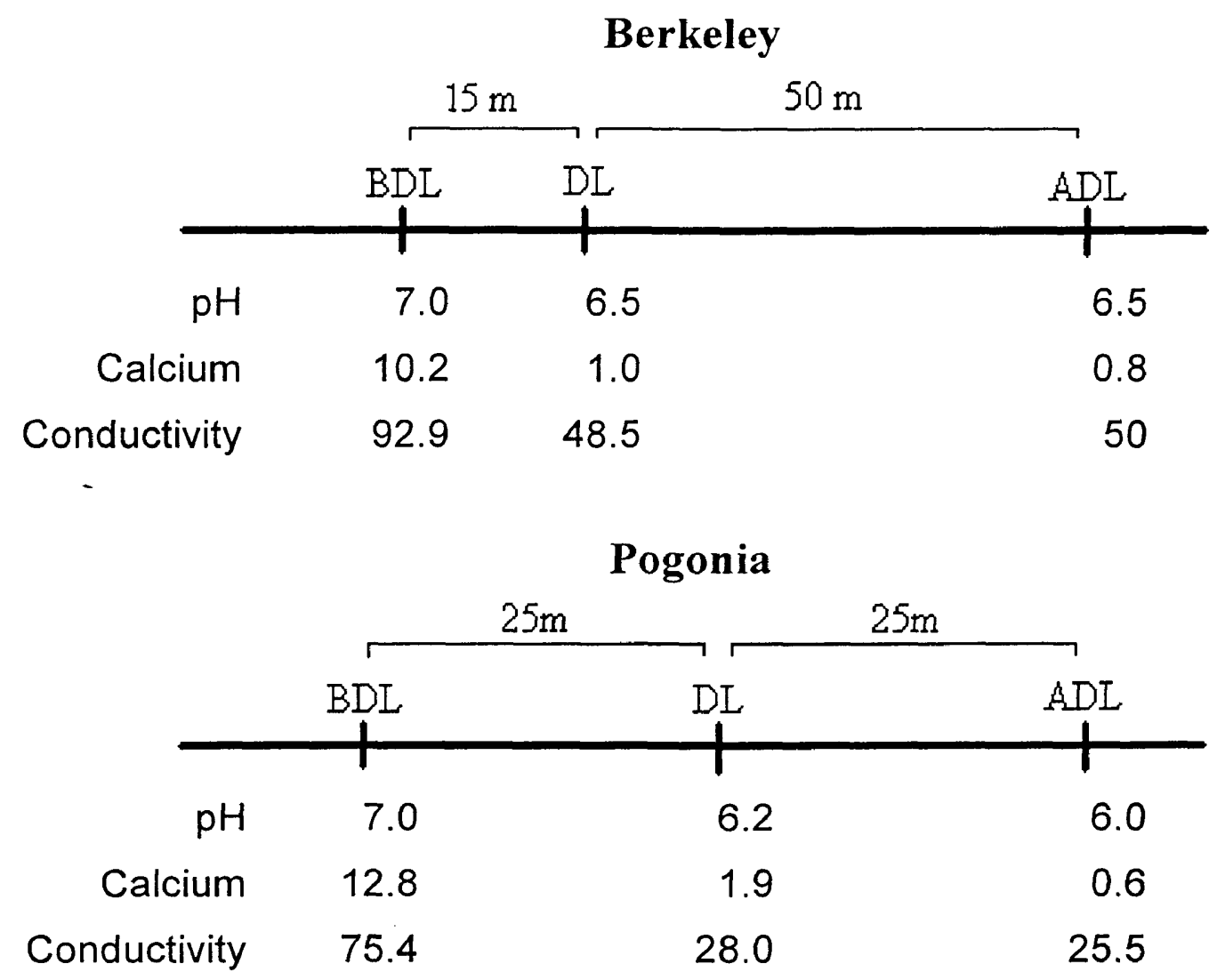

Figure 1. Schematic of Berkeley and Pogonia in the vicinity of the distribution limit (DL). DL represents the distribution limit of the amphipod Gammarus pseudolimnaeus. BDL and ADL are sites below and above the distribution limit, respectively, used in the experiments described in the text. Mean values are reported. Calcium is reported as mg $\mathrm{Ca}^{2+} / 1$ and Conductivities are in $\mu$ mhos. 


\section{Materials and Methods}

\section{General Field and Laboratory Methods}

Amphipods were collected by placing leaf litter into a sieve and retrieving the captured individuals. All individuals used for experimentation were adults ranging from 8 to $14 \mathrm{~mm}$ in length. In the laboratory, the light cycle was kept at 14:10 (L:D) and the temperature was maintained at approximately $20^{\circ} \mathrm{C}$. All amphipods collected for laboratory experiments were kept together in the laboratory in a 55 by $30 \mathrm{~cm}$ tank with water from the collection site for three days prior to use. Chemical determinations were made as follows: calcium tests were performed using the Hach Chemical Company's digital titration method; conductivity measurements were made using a Fischer Traceable conductivity meter; determination of $\mathrm{pH}$ was made using a Fischer Accumet Model $5 \mathrm{pH}$ meter.

\section{Water Balance}

Crustaceans living in dilute media compensate for osmotic influx by increasing the volume of urine production at the antennal gland (Mantel and Farmer 1983). Body water content has been used as an indicator of osmotic stress since, below a threshold ambient osmolarity or below a threshold $\mathrm{pH}$ increased osmotic influx results in increased body water content (Sutcliffe 1971; Hargeby and Petersen 1988; Hargeby 1990). I hypothesized that, if general osmotic failure 
accounted for the absence of G. pseudolimnaeus above the DL, a non-lethal trend involving increasing water content might occur in an upstream direction toward the DL. I collected 30 unsexed amphipods from each of 3 sites in Berkeley: $350 \mathrm{~m}$

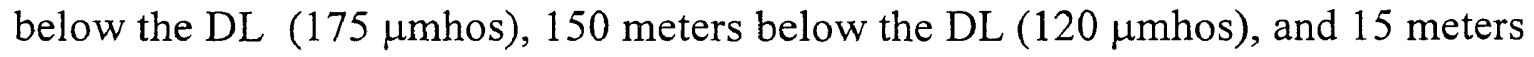
below the DL (93 $\mu$ mhos). The amphipods were brought to the laboratory, randomly paired to provide sufficient mass for accurate measurement, and blotted dry with absorbent paper. Pairs were weighed together to the nearest $0.1 \mathrm{mg}$, dried for 24 hours at $50{ }^{\circ} \mathrm{C}$, and weighed again to determine percent water content.

I also tested, in a field displacement experiment, whether body water content increases in animals maintained in the lethal area of the stream, above the DL. In the field 60 unsexed amphipods were collected from Berkeley, $100 \mathrm{~m}$ below the DL (109 $\mu \mathrm{mhos})$ and randomly distributed between two flow through cages $(20 \mathrm{~cm} \mathrm{x}$ $14 \mathrm{~cm} \times 5 \mathrm{~cm}$ deep). One cage was placed at site BDL and the other at site ADL. Both were retrieved after 5 days since preliminary laboratory experiments indicated that amphipods in ADL water began to experience mortality by day five. Surviving amphipods were treated and measured as above. Additionally, 60 amphipods were collected as above and maintained in aquaria for five days in the laboratory in either $\mathrm{ADL}$ or $\mathrm{BDL}$ water. Survivors were treated and measured as above.

\section{Male and Female Mortality}

There may be sex differences in tolerance of environmental stressors. This experiment tested for differential survival of males and females maintained in water from site $\mathrm{ADL}$ and site $\mathrm{BDL}$. Precopula pairs, which allow rapid determination of 
sex, were collected from Berkeley, $100 \mathrm{~m}$ below the DL. Individuals were separated by sex in the field and brought to the laboratory. Twenty females and 20 males were each assigned randomly to one of two treatment groups: water from the ADL site or from the BDL site. Amphipods were maintained individually without food in glass jars $11 \mathrm{~cm}$ tall by $6 \mathrm{~cm}$ in diameter with $100 \mathrm{ml}$ of water. For 14 days, water in each jar was changed daily, molts and deaths were recorded, and exuviae were removed. The experiment was performed twice.

\section{Chemical Manipulation}

The following laboratory experiment tested the hypotheses that low $\mathrm{pH}$ or insufficient calcium reduces post-molt survival of G. pseudolimnaeus. Control treatments consisted of unaltered $\mathrm{ADL}$ and $\mathrm{BDL}$ water. In one experimental treatment, $\mathrm{pH}$ of $\mathrm{ADL}$ water was raised, through the addition of $\mathrm{NaHCO}_{3}$, to a level empirically observed to support amphipods a short distance below the DL. In another treatment, calcium concentration was similarly increased through the addition of $\mathrm{CaCl}_{2}$. The addition of $\mathrm{NaHCO}_{3}$ or $\mathrm{CaCl}_{2}$ increased the osmolarity of the water, thereby reducing the osmotic gradient between amphipod and medium; this could have reduced mortality, confounding the results. This was controlled for, in the procedural control, through the addition of $\mathrm{NaCl}$ to $\mathrm{ADL}$ water sufficient to match or exceed the total number of ions introduced in either of the two experimental treatments. The addition of $\mathrm{CaCl}_{2}$ or $\mathrm{NaCl}$ did not significantly alter the $\mathrm{pH}$ of the $\mathrm{ADL}$ water in any of the experiments. 
Two replicate experiments were performed using amphipods and water from Berkeley. In the $\mathrm{NaHCO}_{3}$ treatments, $\mathrm{pH}$ was raised to $6.9 \pm 0.2$ and $6.7 \pm 0.2$, respectively. In the $\mathrm{CaCl}_{2}$ treatments the calcium concentration was raised to 10.6 $\pm .9 \mathrm{mg} \mathrm{Ca}^{2+}$ and $10.6 \pm 1.1 \mathrm{mg} \mathrm{Ca}^{2+}$, respectively. One experiment was performed using amphipods and water from Pogonia. The $\mathrm{pH}$ in the $\mathrm{NaHCO}_{3}$ treatment was raised to $6.6 \pm 0.1$; the calcium concentration in the $\mathrm{CaCl}_{2}$ treatment was raised to $10.6 \pm .8 \mathrm{mg} \mathrm{Ca}^{2+}$

In each experiment 100 unsexed amphipods were collected $100 \mathrm{~m}$ below the DL. Twenty amphipods were randomly assigned to each of the five treatment groups. Amphipods were maintained individually in jars with $100 \mathrm{ml}$ water. An $8 \mathrm{~mm}$ disc of beech leaf, previously incubated in stream water for at least three days, was replaced in each jar, every two days as a food source. The water was changed daily, molts and deaths were recorded, and exuviae were removed. Amphipods that molted within 14 days from the start of the experiment were followed until their death or until a total of 14 days had elapsed from their time of molt. 


\section{Results}

\section{Water balance}

Treatment variances were homogenous (Levene's test, $p=.99$ ). ANOVA and multiple comparisons using Tukey's test were applied to the data. The treatments differ $(\mathrm{p}=.002)$. Amphipods collected from $350 \mathrm{~m}$ and $150 \mathrm{~m}$ below the Berkeley DL did not differ significantly in water content $(71.5 \pm 0.13 \%, 72.4 \pm$ $0.15 \%$, respectively; $\mathrm{p}=.45$; Table 1 ). Water content of amphipods collected $15 \mathrm{~m}$ below the DL $(69.7 \pm 0.12 \%)$ was significantly lower than that of amphipods collected $150 \mathrm{~m}$ below the DL $(\mathrm{p}=.002)$, and those collected $350 \mathrm{~m}$ below the DL $(p=.04)$

In the field displacement experiment 24 individuals survived in the ADL treatment and 28 in the BDL treatment. The surviving individuals were randomly paired for accurate weighing resulting in sample sizes of 12 and 14, respectively. Treatments variances were homogenous (Levene's test, $\mathrm{p}=.53$ ). An unpaired t-test with standard error adjusted for unequal sample sizes was applied to the data. Percent water content of amphipods maintained for 5 days at the ADL site $(72.4 \pm$ $0.74 \%)$ did not differ significantly $(\mathrm{p}=.66)$ from those at the BDL site $(72.7 \pm$ $0.08 \%)$

In the laboratory water balance experiment 14 individuals survived in the ADL treatment and 26 in the BDL treatment, providing sample sizes of 7 and 13 , 


\begin{tabular}{llll}
\hline Field Survey & \multicolumn{4}{c}{ Meters Downstream from DL } \\
& \multicolumn{1}{c}{15} & 150 & 350 \\
\cline { 2 - 4 }$\%$ Water Content & $69.7 \pm 0.12 \%(15)$ & $72.4 \pm 0.15 \%(15)$ & $71.5 \pm 0.13 \%(15)$ \\
\hline
\end{tabular}

\section{Field}

Experiment

\section{Treatment}

$\mathrm{ADL} \quad \mathrm{BDL}$

$\%$ Water Content $72.4 \pm 0.74 \%(12) \quad 72.6 \pm 0.08 \%(14)$

\section{Laboratory Experiment}

\section{Treatment}

\begin{tabular}{ccc} 
& ADL & BDL \\
\cline { 2 - 3 } & $72.1 \pm 0.17(7)$ & $73.0 \pm 0.14(13)$ \\
\hline
\end{tabular}

Table 1. Results from the three water balance experiments. The mean percent water content with the standard error is presented for each treatment with the sample size in parentheses. In the field survey amphipods collected from $15 \mathrm{~m}$ below the distribution limit (DL) had significantly lower percent water content $(p=.02)$ than the other two treatments, which did not differ. The percent water content of amphipods in the ADL and BDL treatments did not significantly differ in either the field or laboratory experiments. 
respectively. The treatment variances were homogenous (Levene's test, $\mathrm{p}=.47$ ) and an adjusted t-test was applied as above. Amphipods maintained in ADL water (72.1 $\pm 0.17 \%)$ did not differ $(p=.25)$ from those in BDL water $(73.0 \pm 0.14 \%)$.

\section{Male and Female Mortality}

The survival curves were analyzed by proportional model regression analysis using StatView Survival Tools. For comparisons among curves, $\alpha$ was adjusted to .008 for an experimentwise error rate of .05 . In both experiments $A D L$ females experienced higher mortality than BDL females ( $\mathrm{p}<.0001$ for both). Mortality of females and males maintained in the same water, ADL or BDL, did not differ significantly in either experiment (see Figures 2,3 for $\mathrm{p}$ values). However, in the first experiment $\mathrm{ADL}$ males tended to survive longer than $\mathrm{ADL}$ females $(\mathrm{p}=$ $.06)$ and males in BDL water tended to survive for less time than BDL females $(\mathrm{p}=$ .06). Females in ADL water tended to have higher mortality than males in BDL water $(\mathrm{p}=.024 ; .016)$; ADL females had significantly higher mortality than BDL females $(p=.0001 ;<.0001$; figures 2,3$)$. Males in ADL water tended to have greater mortality than males in BDL water $(\mathrm{p}=.12 ; \mathrm{p}=.011)$.

In both experiments mortality appeared to be closely associated with time of molt in both sexes. In the two experiments 48 females and 17 males molted. In both experiments no amphipods maintained in ADL water survived for longer than 2 days post-molt and most lived less than or equal to 1 day post-molt. Most amphipods maintained in BDL water, regardless of sex, lived longer than 5 days post-molt. 


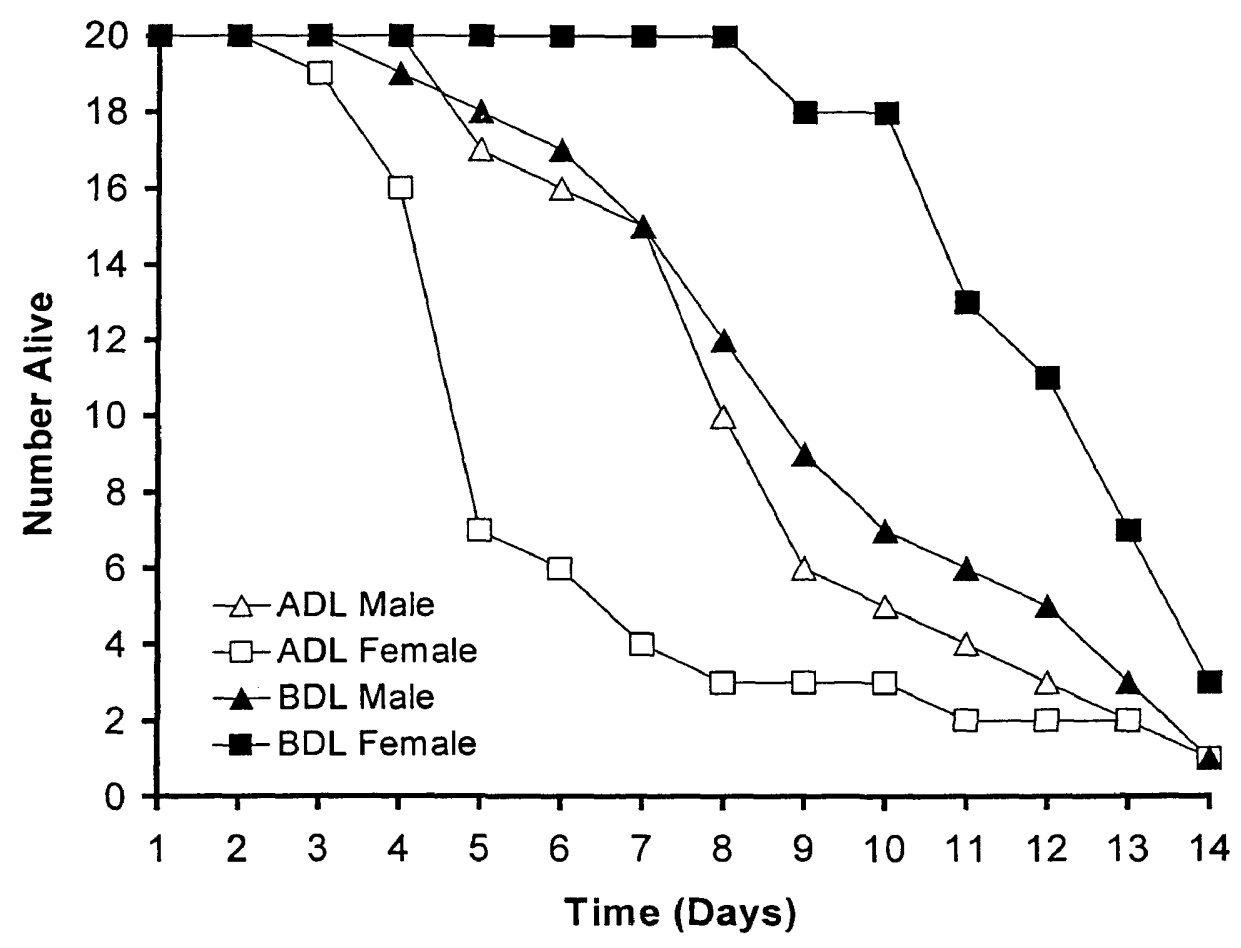

Figure 2. Survival curves for male and female amphipods from Berkeley maintained in ADL and BDL water in experiment 1. Proportional hazards model regression analysis with $\alpha$ adjusted to .008 gave the following results: The curves differ $(p<.0001)$. ADL males do not differ significantly from ADL females $(p=.06)$. BDL males and females do not differ $(p=.06)$. BDL females survive longer than ADL females $(p<.0001)$ but do not differ from ADL males $(p=.03)$. BDL males do not differ from ADL females $(p=.02)$ or from ADL males $(p=.7)$. 


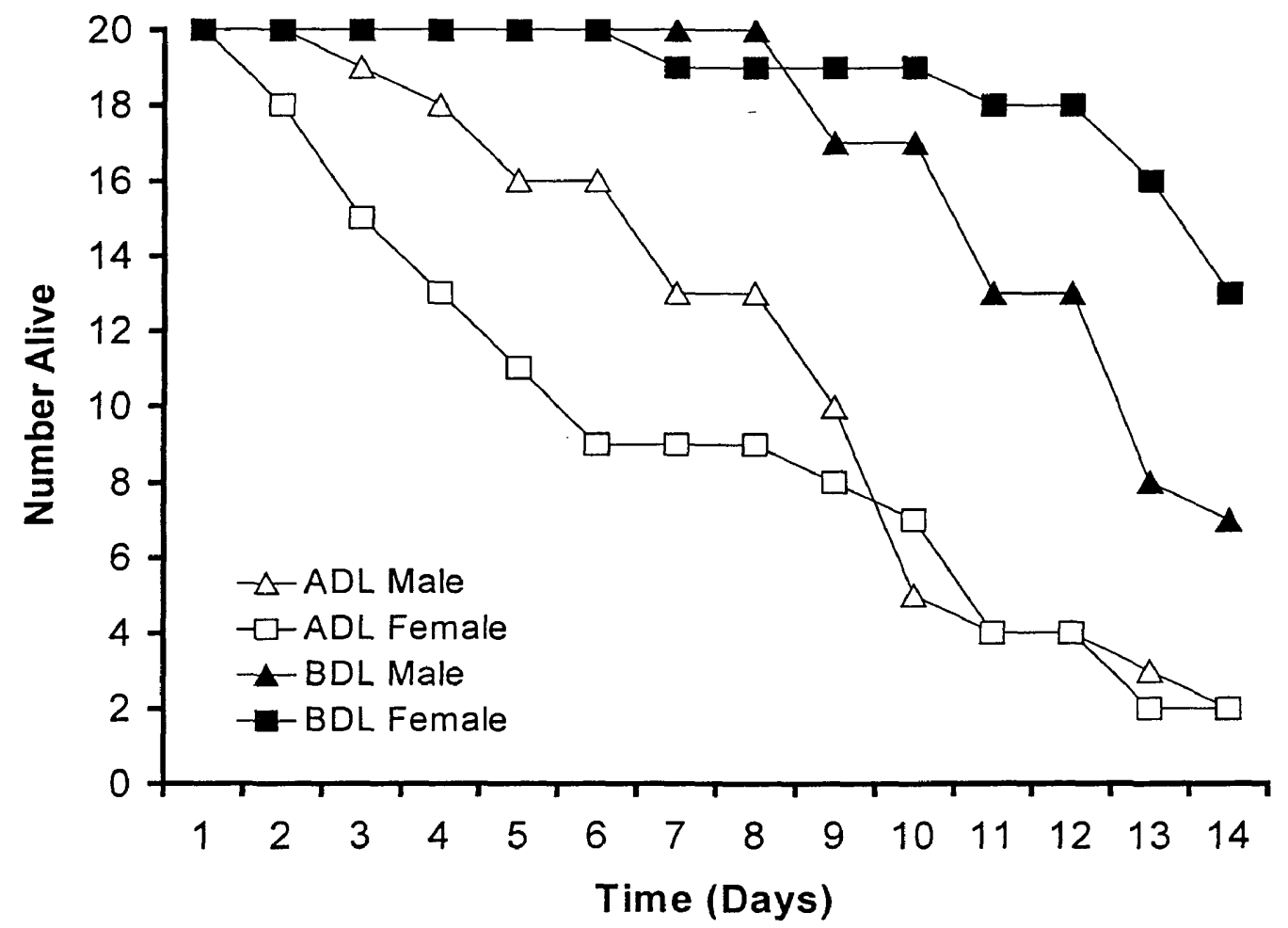

Figure 3. Survival curves for male and female amphipods from Berkeley maintained in ADL and BDL water in experiment 2. Proportional hazards model regression analysis gave the following results: The curves differ $(p<.0001)$. ADL males did not differ significantly from ADL females $(p=.86)$. BDL males and females did not differ $(p=.082)$. BDL males survived longer than ADL males $(p=.011)$ and females $(p=.016)$. BDL females survived longer than ADL males $(p<.0001)$ and females $(p=.0001)$. 


\section{Chemical manipulation}

Consistent with Mahon's (1997) suggestion and the observations reported above, differential mortality rates in the chemical manipulation experiment resulted from differential post-molt survival in the various treatments. In all treatments mortality occurred in some individuals prior to molting but did not differ significantly among treatments (proportional model regression analysis; first Berkeley experiment, $\mathrm{p}=.56$; second Berkeley experiment, $\mathrm{p}=.87$; Pogonia experiment, $\mathrm{p}=.47)$.

The results for post-molt survival of the two Berkeley experiments were qualitatively and quantitatively similar and the data were combined in a single analysis. The $\log _{10}(X+1)$ transformed data (Zar 1996) had homogenous variance (Levene's test; $\mathrm{p}=.79$ ). The transformed data were analyzed in a 2-way ANOVA with treatment as 1 factor with 5 levels and experiment as the second factor with 2 levels. The effect of treatment was significant $(p<.0001)$. There was neither an effect of experiment $(\mathrm{p}=.22)$, nor a significant interaction $(\mathrm{p}=.51)$ and so the data were collapsed across the second factor for multiple comparisons using Tukey's test.

Amphipods in the BDL treatment survived an average of 9.6 days post-molt, significantly longer than amphipods in the ADL treatment, which survived an average of 1.9 days ( $p<.0001$, Figure 4$)$. The ADL and the $\mathrm{NaCl}$ treatments did not differ significantly ( $\mathrm{p}>.5)$. Amphipods in the $\mathrm{CaCl}_{2}$ treatment survived an average of 8.9 days post-molt, longer than the ADL treatment $(p<.0001)$, and not significantly 


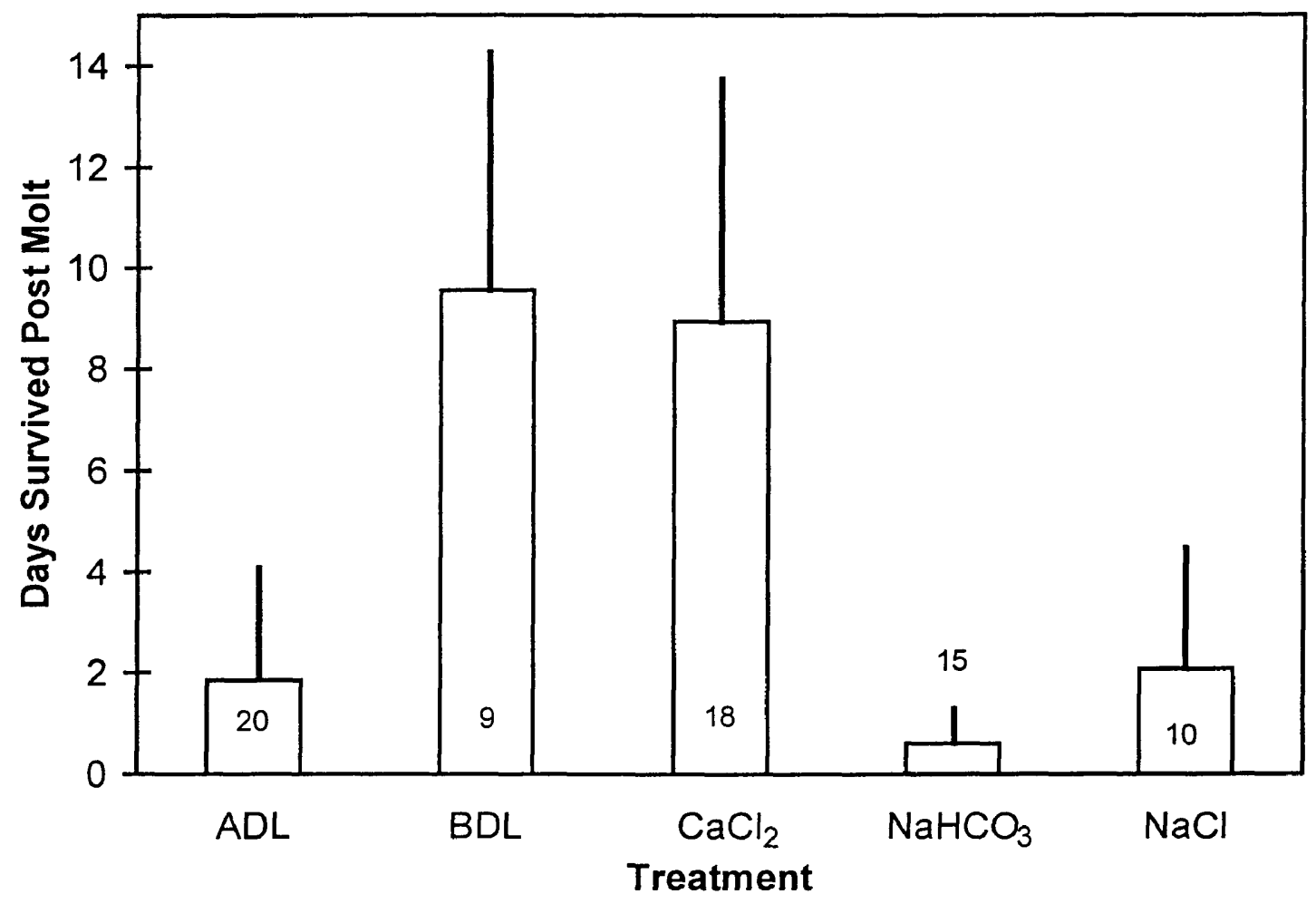

Figure 4. Results from the 2 chemical manipulation experiments with amphipods and water from Berkeley. Error presented as standard deviations; numbers in bars are sample sizes. The treatments differ (2-way ANOVA, $\mathrm{p}<.0001)$ but there was no effect of experiment $(p=.22)$ nor an interaction $(p=.51)$. Multiple comparisons were made with Tukey's test after collapsing data across experiments. ADL and $\mathrm{NaCl}$ do not differ ( $p>.5$ ) and $\mathrm{NaHCO}_{3}$ does not differ from ADL $(\mathrm{p}=.087)$. BDL and $\mathrm{CaCl}_{2}$ do not differ $(\mathrm{p}>.5)$ and both are significantly greater than ADL ( $p<.0001$ for both). 
different from the BDL group ( $\mathrm{p}>.5)$. The $\mathrm{NaHCO}_{3}$ group survived an average of 0.6 days post-molt, which was not significantly different from the ADL group $(\mathrm{p}=.087)$.

In the Pogonia experiment the $\log _{10}(\mathrm{X}+1)$ transformed data had homogenous variance $(\mathrm{p}=.24)$. The transformed data were analyzed with a 1-way ANOVA which was significant $(\mathrm{p}<.0001)$. Multiple comparisons were performed using Tukey's test.

Results were similar to those for Berkeley. Amphipods in the BDL treatment survived an average of 8.3 days post-molt, significantly longer than amphipods in the ADL treatment, which survived an average of 1 day post-molt $(\mathrm{p}<.0001 ;$ Figure 5$)$. The ADL and $\mathrm{NaCl}$ treatments did not differ significantly (p>.5). Amphipods in the $\mathrm{CaCl}_{2}$ treatment survived an average of 10.7 days postmolt, longer than the ADL treatment $(\mathrm{p}<.0001)$, and not significantly different from the BDL group $(\mathrm{p}=.33)$. The $\mathrm{NaHCO}_{3}$ group survived an average of 1 day postmolt, which was not significantly different from the ADL group ( $p>.5)$.

Although potential food in the form of beech leaf detritus was provided for all experiments, amphipods consumed very little. 


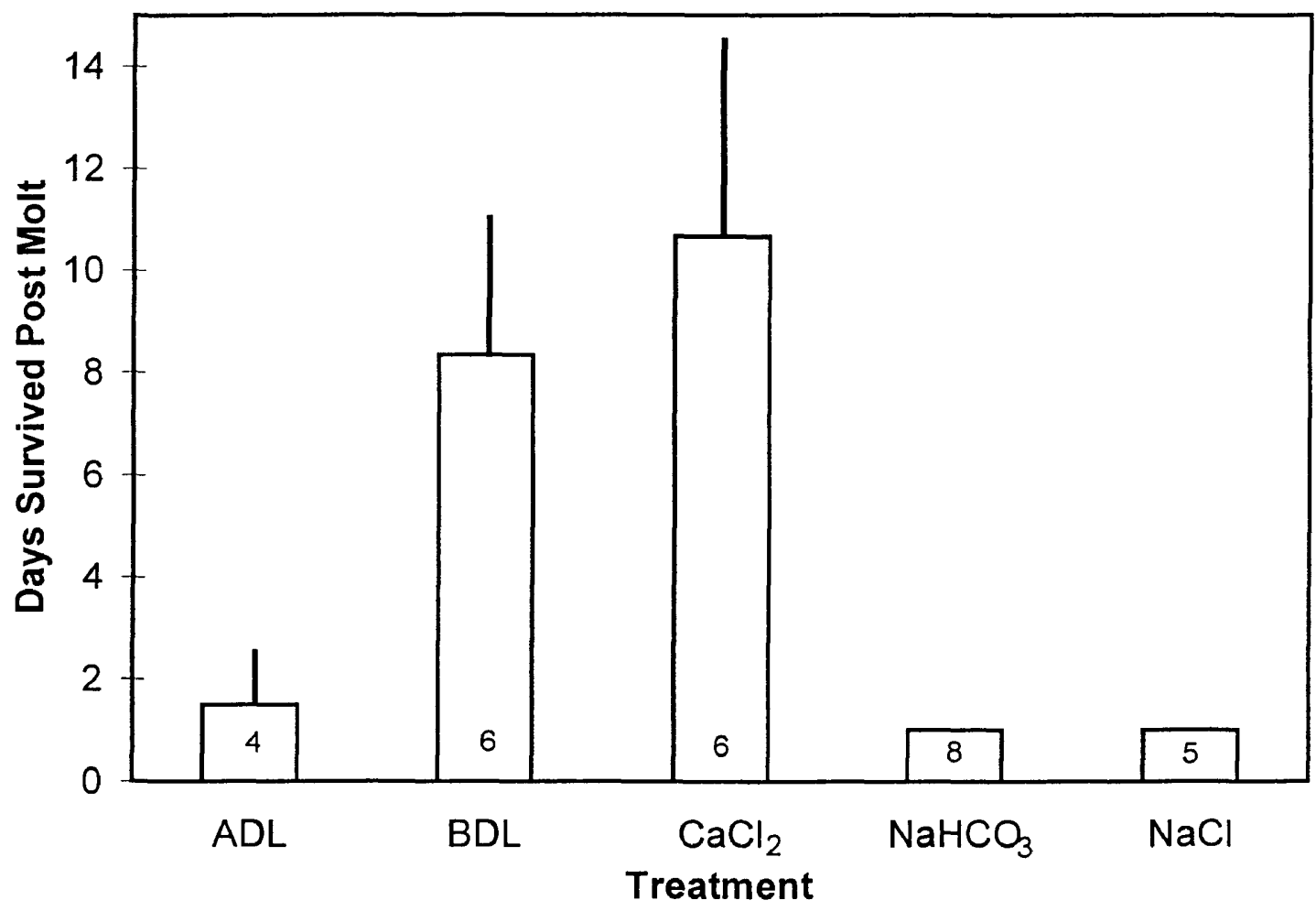

Figure 5. Results from the chemical manipulation experiment with amphipods and water from Pogonia. The treatments differ (1-way ANOVA, $\mathrm{p}<.0001$ ). ADL, NaCl, and $\mathrm{NaHCO}_{3}$ do not differ ( $>$.5). BDL and $\mathrm{CaCl}_{2}$ do not differ $(\mathrm{p}=.33)$ and both are significantly greater than $\mathrm{ADL}(\mathrm{p}<.0001 ; \mathrm{p}<.0001)$. All amphipods in the $\mathrm{NaHCO}_{3}$ and $\mathrm{NaCl}$ treatment groups died after 1 day post-molt, resulting in an estimated variance of 0 . 


\section{Discussion}

Amphipods displaced above the DL in flow-through cages, in both Berkeley or Pogonia, experienced higher mortality than those in cages below the DL (Mahon 1997). Many biotic or abiotic factors could potentially account for this. However, the $2 \mathrm{~mm}$ mesh on the flow-through cages used in Mahon's work excluded all likely predators and competitors. The change from abundance to absence in the two streams occurs over only a few meters. Furthermore, the chemical conditions found at the distribution limits of the two streams are similar in $\mathrm{pH}$ and calcium concentrations (Figure 1). This suggests some aspect of water chemistry as the limiting factor.

The water at the DL in Pogonia and Berkeley is very low in dissolved materials. For crustaceans living in dilute media, concentration gradients drive ion loss and osmotic influx which is typically balanced by enhanced ion uptake and an overall reduction in integument permeability. However, while the permeability of the gills, gut, and antennal glands is, in most cases, generally reduced in freshwater species with respect to those structures in marine species, the need to respire, absorb nutrients, and excrete wastes limits this reduction (Mantel and Farmer 1983). Body water content has been used as an indicator of osmotic stress since below a threshold ambient osmolarity, or in depressed $\mathrm{pH}$, increased osmotic influx 
results in increased body water content (Sutcliffe 1971; Hargeby and Petersen 1988; Hargeby 1990). For example, when the brackish amphipod G. duebeni is displaced into dilute media its body water content increases from $78 \%$ to $80 \%$. G. pulex maintained in a stream with a $\mathrm{pH}$ around 7 had a body water content of $73 \%$ while those maintained in streams with lower pH's had body water contents up to $80 \%$ (Hargeby 1990).

Amphipods maintained in ADL water in the field and in the laboratory showed only slight and insignificant increases in body water content $(0.2 \%$ and $0.9 \%$, respectively). Furthermore, in the field survey, the lower body water content of amphipods collected at site BDL ( $15 \mathrm{~m}$ below the DL), compared to the other 2 sites further downstream of the distribution limit, is inconsistent with the hypothesis that amphipods nearer the distribution limit are progressively more osmotically stressed. Therefore, a general osmoregulatory problem does not appear to prevent intermolt animals from living further upstream.

There may be sex differences in tolerance of environmental stressors. In the male and female mortality experiment, no significant differences were found between males and females in either ADL or BDL water. However, the p-values were very close to .05 (figure 2,3) and a real difference may exist. In the BDL water, males tended to have higher mortality than females. This may represent a lower threshold for laboratory stress in males, a difference in life span between the sexes, or some selection bias related to choosing males from precopula pairs. Males collected from precopula pairs varied widely in size and, presumably, age. 
Energy expended in mate guarding could lower males' tolerance for stressors, but females may also have additional energy needs associated with reproduction.

The lower survival of females in ADL water, however, is probably a result of their higher molting rates. In the 2 experiments 48 females molted, compared to 17 males. This is probably a direct result of their collection from precopula pairs. While the males could have been at almost any stage in the molt cycle, females in precopula pairs are typically at late stage $\mathrm{C}$, shortly before molt-stage (Wright 1980). Analysis of mortality in relation to molt in the 2 water types revealed a striking pattern. While male and female amphipods in BDL water survived many days post-molt, those in ADL water rarely lived longer than 1 day post-molt. Unfortunately, I tracked the amphipods for only the 14 days of the experiment and not until the death of all the molted animals. The resulting data censor the survival of 16 of the amphipods in BDL treatments and 1 in the ADL treatments. Nonetheless, the resulting conservative estimate of post-molt survival clearly demonstrates that survival post-molt for males and females is acutely impacted by the water in which the amphipods are maintained. Most of the difference in mortality between the ADL and BDL treatments is due to differential mortality at molt. These findings confirm Mahon's (1997) speculation that death above the DL is largely molt related.

I hypothesized that low $\mathrm{pH}$ or low calcium concentration of water above the distribution limit in these streams is limiting to G. pseudolimnaeus at the time of molt. I tested this hypothesis through the addition of $\mathrm{CaCl}_{2}$ and $\mathrm{NaHCO}_{3}$ to $\mathrm{ADL}$ 
water, in separate treatments, to raise the calcium concentration and $\mathrm{pH}$, respectively, to levels found just below the DL, where amphipods were always present. The rise in $\mathrm{pH}$ associated with the addition of $\mathrm{NaHCO}_{3}$ did not decrease mortality. However, the effect of calcium was clear. Increasing ADL calcium concentration to $10.6 \mathrm{mg} \mathrm{Ca}^{2+}$ resulted in a reduction in post-molt mortality to levels found in BDL water in the 3 experiments. No increase in survival over the ADL group occured upon addition of an equal total number of $\mathrm{Na}^{+}$and $\mathrm{Cl}^{-}$ions. Thus, the increase in survival observed in the $\mathrm{CaCl}_{2}$ treatment could not have been due to the rise in ambient osmolarity associated with the addition of $\mathrm{Ca}^{+}$and $\mathrm{Cl}^{-}$ ions. Ambient calcium concentration may impact post-molt survival through an epidermal membrane association or as a source for maintaining internal calcium concentration.

In crustaceans, permeability to water can increase by as much as two times intermolt levels during ecdysis (Lockwood and Inman 1973). Increased water uptake results in swelling which aids in the expansion of the new exoskeleton (Mantel and Farmer1983). However, with the loss of the barrier of the exoskeleton, this probably represents the period of greatest osmotic stress (Hargeby and Petersen 1988). Calcium is important in many animals for maintaining a relatively impermeable epithelial membrane. In fish gills, calcium is bound to negatively charged proteins on the surface of the epithelium at tight junctions, stabilizing the membrane, and thus lowering permeability (Hunn 1985; McDonald 1983). Gill permeability of fish typically increases with decreasing ambient calcium 
concentrations (Potts and Flemming 1970; McWilliams 1983; Ogasawara and Hirano 1984; Pic and Maetz 1981). Furthermore, in some fish low pH may displace calcium from its bound sites on the epithelium at cell tight junctions leading to increased permeability. This effect is minimized in high calcium concentrations (McWilliams 1983; McDonald 1983). Ionoregulatory failure, probably through this process, is the primary mechanism of mortality in moderately low $\mathrm{pH}$ (McDonald et al. 1980).

However, the role of calcium in the permeability of the crustacean membrane is less clear and subject to interspecific variation. The apparent water permeability of the crab Cherax destructor and the crayfish Astacus astacus show little relation to calcium concentration and the crab Carcinus maenas increases its permeability with increased ambient calcium (Rasmussen and Bjerregaard 1995). However, the crab Cancer magister experiences a reduction in permeability to $\mathrm{Na}^{+}$ ions in high calcium media (Robinson and Potts 1979). Unlike in fish, calcium concentration had little effect on sodium loss in the cladocerans Daphnia magna and Acantholeberis curvirostris in low pH (Potts and Fryer 1979) or on the mortality of the amphipod G. fossarum in low pH (Meinel et al. 1985).

Ecdysis is also characterized by the loss of the majority of body calcium, $96 \%$ in G. pulex, both into solution and in the form of the exuviae (Wright 1980). Immediately after molt the calcium balance is shifted to rapid uptake, though the rate of this process is dependent on ambient calcium concentration (Wright 1980) and $\mathrm{pH}$ (Malley 1980). Therefore, G. pseudolimnaeus may survive above the DL 
during intermolt through retention of body calcium, but calcium concentration above the DL may be too low for efficient uptake at molt. This would prevent the calcification of the new exoskeleton, but this alone in a culture jar, in the absence of predators, would be unlikely to result in immediate mortality. However, if calcium loss during ecdysis, without efficient uptake, briefly drops body calcium below concentrations necessary for general internal functions, an inability to rapidly reaquire calcium from the environment might result in mortality.

In the Berkeley and Pogonia chemical manipulation experiments, amphipods maintained in $\mathrm{BDL}$ water or in $\mathrm{ADL}$ water with additional calcium lived an average of about 9 days post-molt. Therefore, the mechanism of mortality in these groups is probably not molt-related. However, this is probably a higher mortality than found in the field below the DL. Conditions may have been more stressful in some respect in the laboratory than would be the case in the field. It would be instructive to follow amphipods in BDL water in the laboratory to determine if any survive to a second molt. Although periodic checks revealed no hypoxia in the culture jars and water was changed daily to prevent waste build up, a less static environment may be important for amphipod survival.

Insufficient nutrition may also have played a part in laboratory-related stress. Beech are abundant in the forest surrounding the study streams and the stream water-incubated beech leaves were included as an energy source for the chemical manipulation experiments. However, throughout the experiment, few amphipods ate visible portions of the leaf discs. Fungal colonies are important in the 
palatability of leaf litter to amphipods (Barlocher and Kendrick 1973) and the three day incubation period may not have been sufficient for establishment of important fungal colonies. It is also possible that beech leaves may, in some other way, be unacceptable as a food source. Osmoregulation requires substantial energetic input (Nery and Santos 1993) and energetic demands in ADL water may exceed those of BDL water. This could be especially important to amphipods molting later in the experiments when energy reserves between the groups of animals would possibly be most different. However, there is probably no role for food as a calcium source as uptake through the gut from food was not a significant source of ions in four species of talitrid amphipod (Morritt 1989). 


\section{Conclusions and Future Directions}

Fresh waters with both low conductivities and low calcium concentrations are common throughout the Appalachian mountains and in much of the northern portion of the United States and into Canada. An understanding of the role of calcium as a limiting factor for other crustacean species in these and other areas would be valuable to both biogeography and to biomonitoring efforts. All crustaceans lose a significant fraction of their body calcium at molt in the form of the exuviae and substantial loss from the haemolymph and other compartments has been reported in the crabs Callinectes (Hecht 1914) and Uca (Kleinholz 1941), the crayfish Austropotamobius (Greenaway 1974), and the amphipod Gammarus (Wright 1980). Therefore, low calcium concentration may be a factor in the distribution of many other crustaceans in areas depauparate in calcareous materials.

No systematic survey of the distribution of G. pseudolimnaeus in relation to water chemistry has been published. Such a study would be valuable in determining the applicability of these results to G. pseudolimnaeus distribution in other areas. Furthermore, more manipulative experiments such as those described here need to be performed on other species. However, an understanding of the mechanism of mortality for G. pseudolimnaeus in low calcium waters would provide a stronger basis for predicting the importance of calcium in other situations. The connection between molt and mortality does not resolve the role calcium plays in promoting post-molt survival; there are many possible explanations as explored in the discussion.

Furthermore, these results should not be interpreted as an absolute lower calcium limit 
for G. pseudolimnaeus. The calcium concentration at the distribution limit in Berkeley is $1 \mathrm{mg} \mathrm{Ca}{ }^{2+} / 1$ and at the limit in Pogonia is $1.9 \mathrm{mg} \mathrm{Ca}^{2+} / 1$. In the chemical manipulation experiments calcium concentration was raised to around $10 \mathrm{mg} \mathrm{Ca}^{2+} / 1$, much higher than that found at the distribution limits. Therefore we cannot conclude based on this evidence that calcium alone is sufficient to explain the observed distribution limits. The difference in the calcium concentration at the distribution limits in the two streams may be explained by an interaction with other chemical factors that moderate the lower physiological limit for G. pseudolimnaeus.

Therefore, more study is needed with experiments like those described here as well as experiments designed to address the physiological mechanisms involved in calcium/molt-related mortality. I give here three examples of experiments that could begin to explore this physiological question: The osmolarity of ADL water could be raised through the addition of an inert organic molecule like sucrose and the effect on post-molt mortality determined. Decreased mortality would suggest that post-molt mortality in low calcium media is somehow related to osmoregulation. Tracer studies using labeled water (see Lockwood and Inman 1973) could be used to determine if $G$. pseudolimnaeus's permeability to water and ions changes with ambient calcium concentrations. This experiment would be especially valuable if performed shortly after molt. Positive results would suggest the importance of calcium in maintaining the impermeability of the membrane. Finally, amphipods could be allowed to molt in BDL water in which a calcium channel antagonist had been introduced. Reduced survival under these conditions would suggest that the role of calcium is internal, and that membrane-bound calcium is not an important factor. 


\section{References}

Barlocher, F. and B. Kendrick. 1973. Fungi and food preferences of Gammarus pseudolimnaeus. Archiv für Hydrobiologie 72(4):501-516.

Glazier, D.S. and J.L. Gooch. 1987. Macroinvertebrate asemblages in Pennsylvania (U.S.A.) springs. Hydrobiologia 150:33-43.

Grapentine, L.C. and D.M. Rosenberg. 1992. Responses of the freshwater amphipod Hyalella azteca to environmental acidification. Canadian Journal of Fisheries and Aquatic Sciences 49:52-64.

Greenaway, P. 1974. Calcium balance at the premoult stage of the freshwater crayfish Austropotamobius pallipes (Lereboullet). Journal of Experimental Biology 61:35-45.

Hanson, D.L. and T.F. Waters. 1974. Recovery of standing crop and preduction rate of a brook trout population in a flood-damaged stream. Transactions of the North American Fisheries Society 103:431-439.

Hargeby, A. 1990. Effects of $\mathrm{pH}$, humic substances and animal interactions on survival and physiologcial status of Asellus aquaticus L. and Gammarus pulex (L.). Oecologia 82:348-354.

Hargeby, A. and R.C. Petersen. 1988. Effects of low pH and humus on the survivorship, growth and feeding of Gammarus pulex (L.) (Amphipoda). Freshwater Biology 19:235-247.

Havas, M. and T.C. Hutchinson. 1983. Effect of low pH on the chemical composition of aquatic invertebrates from tundra ponds at the Smoking Hills, N.W.T., Canada. Canandian Journal of Zoology 61:241-249.

Hecht, S. 1914. Note on formation of calcium during the moulting of the blue crab Callinectes sapidus. Science. 39:108.

Hilton, J., D.W. Sutcliffe, T.R. Carrick, and E. Rigg. 1984. Major inorganic components in some freshwater crustaceans (Malacostra), their exuviae and food items, and thermogravimetric-differential thermal analysis of organic and ash components. Comparative Biochemistry and Physiology 77A(1):13-22. 
Hunn, J.B. 1985. Role of calcium in gill function in freshwater fishes. Comparative Biochemistry and Physiology 82A(3):543-547.

Kleinholz, L.H. 1941. Moulting and calcium deposition in decapod crustaceans. Journal of Cellular and Comparative Physiology. 18:101-107.

Lockwood, A.P.M. and C.B.E. Inman. 1973. Changes in the apparent permeability to water at moult in the amphipod Gammarus duebeni and the isopod Idotea linearis. Comparative Biochemistry and Physiology 44A:943-952.

Macan, T.T. 1961. Factors that limit the range of freshwater animals. Biological Reviews of the Cambridge Philosophical Society 36:151-198.

Mahon, S. 1997. Distribution and ecology of freshwater amphipoda in the lake matoaka/college woods area, Williamsburg, Virginia. M.A. Thesis., The College of William and Mary in Virginia.

Malley, D.F. 1980. Decreased survival and calcium uptake by the crayfish Orconectes virilis in low pH. Canadian Journal of Fisheries and Aquatic Science. 37: 364-372.

Mangum, C.P. 1983. Oxygen transport in the blood. p.p. 373-429 in L.H. Mantel (editor). Internal Anatomy and Physiological Regulation, Volume 5 of D.E. Bliss (editor). The Biology of Crustacea. Academic Press, New York.

Mantel, H. And L.L. Farmer 1983. Osmotic and Ionic Regulation. p.p. 54-162 in L.H. Mantel (editor). Internal Anatomy and Physiological Regulation, Volume 5 of D.E. Bliss (editor). The Biology of Crustacea. Academic Press, New York.

McDonald, D.G. 1983. The effects of $\mathrm{H}^{+}$upon the gills of freshwater fish. Canadian Journal of Zoology 61:691-703.

McDonald, D.G., H. Hobe, and C.M. Wood. 1980. The influence of calcium on the physiological responses of the rainbow trout, Salmo gairdneri, to low environmental pH. Journal of Experimental Biology 88:109-131.

McWilliams, P.G. 1983. An investigation of the loss of bound calcium from the gills of the brown trout, Salmo trutta, in acid media. Comparative Biochemistry and Physiology 74A(1):107-116.

Meinel, V.W., U. Matthias, and S. Zimmermann. 1985. Okophysiologische untersuchungen zur sauretoleranz von Gammarus fossarum (Koch). Archiv für Hydrobiologie 104(2):287-302. 
Morritt, D., 1989. Ionic regulation in littoral and terrestrial amphipods. Journal of Experimental Marine Biology and Ecology 132:53-67.

Nery, L.E.M. and E.A. Santos. 1993. Carbohydrate metabolism during osmoregulation in Chasmagnathus granulata Dana, 1851 (Crustacea, Decapoda). Comparative Biochemistry and Physiology 106B(3):747-753.

Ogasawara, T. and T. Hirano. 1984. Effects of prolactin and environmental calcium on osmotic water permeability of the gills in the eel, Anguilla japonica. General and Comparative Endocrinology 53:315-324.

Okland, K.A. and J. Okland. 1985. Factor interaction influencing the distribution of the freshwater "shrimp" Gammarus. Oecologia 66:364-367.

Okland, J and K.A. Okland. 1986. The effects of acid deposition on benthic animals in lakes and streams. Experientia 42:471-486.

Otto, C., and B.S. Svensson. 1983. Properties of acid brown water streams in South Sweden. Archiv für Hydrobiologie 99:15-36.

Pennak, R.W. 1978. Fresh-water invertebrates of the United States. John Wiley and Sons, New York.

Pic, P. and J. Maetz. 1981. Role of external calcium in sodium and chloride transport in the gills of seawater-adapted Mugil capito. Journal of Comparative Physiology B 141:511-521.

Pinkster, S. 1972. On members of the Gammarus pulex-group (CrustaceaAmphipoda) from western europe. Budragen Tot De Dierkunde. 42(2):164-191.

Potts, W.T.W. and W.R. Flemming. 1970. The effects of prolactin and divalent ions on the permeability to water of Fundulus kansae. Journal of Experimental Biology 53:317-327.

Potts, W.T.W and G. Fryer. 1979. The effects of $\mathrm{pH}$ and salt content on sodium balance in Daphnia magna and Acantholeberis curvirostris (Crustacea: Cladocera). Journal of Comparative Physiology 129:289-294.

Rasmussen, A.D. and P. Bjerregaard. 1995. The effect of salinity and calcium concentration on the apparent water permeability of Cherax destructor, Astacus astacus, and Carcinus maenas (Decapoda, Crustacea). Comparative Biochemistry and Physiology 111A(1):171-175.

Robinson, G.D. and W.T.W. Potts. 1979. Ion fluxes and diffusion potentials in the dungeness crab, Cancer magister. Journal of Comparative Physiology B 131:285-292. 
Schell, V.A. and J.J. Kerekes. 1989. Distribution, abundance and biomass of benthic macroinvertebrates relative to $\mathrm{pH}$ and nutrients in eight lakes of Nova Scotia, Canada. Water, Air, and Soil Polution 46:359-374.

Schrimpff, E. and F. Foeckler. 1985. Gammarids in streams of northeastern Bavaria, F.R.G. I. Prediction of their general occurrence by selected hydrochemical variables. Archiv für Hydrobiologie 103(4):479-495.

Stevenson, J.R. 1985. Dynamics of the integument. p.p. 2-43 in D.E. Bliss and L.H. Mantel (editors). Integument, Pigments, and Hormonal Processes, Volume 9 of D.E. Bliss (editor) The Biology of Crustacea. Academic Press, New York.

Stephenson, M. and G.L. Mackie. 1986. Lake acidification as a limiting factor in the distribution of the freshwater amphipod Hyalella azteca. Canadian Journal of Fisheries and Aquatic Sciences 43:288-292.

Sutcliffe, D.W. 1971. Regulation of water and some ions in Gammarids (Amphipoda). Journal of Experimental Biology 55:325-344.

Sutcliffe, D.W. and T.R. Carrick. 1973. Studies on mountain streams in the English lake district. Freshwater Biology 3:437-462.

Taylor, A.C. and J.I. Spicer. 1986. Oxygen-transporting properties of the blood of two semi-terrestrial amphipods, Orchestia gammarellus (Pallas) and O. mediterranea (Costa). Journal of Experimental Marine Biology and Ecology 97:135-150.

Wright, D.A. 1980. Calcium balance in premoult and post-moult Gammarus pulex (Amphipoda). Freshwater Biology 10:571-579.

Zar, J.H. 1996. Biostatistical Analysis. Prentice Hall, Upper Sadle River, New Jersey. 


\section{Vita}

John Kinsley Zehmer was born in Newport News Virginia where he attended Hampton Roads Academy, graduating in 1989. He pursued a Bachelor of Science in biology at Guilford College in Greensboro, North Carolina, graduating in 1993. After working for three years after college as a river guide and kayak instructor he entered The College of William and Mary to study freshwater ecology, finishing with a Master of Arts in 1998. He will begin his Ph.D. at Arizona State University in the fall of 1998 working in Jeff Hazel's lab on lipid biochemistry / membrane physiology using rainbow trout and Tilapia as study organisms. 